\title{
Modelling of conspicuity-related motorcycle accidents in Seremban and Shah Alam, Malaysia
}

\begin{abstract}
Preliminary analysis of the short-term impact of a running headlights intervention revealed that there has been a significant drop in conspicuity-related motorcycle accidents in the pilot areas, Seremban and Shah Alam, Malaysia. This paper attempts to look in more detail at conspicuity-related accidents involving motorcycles. The aim of the analysis was to establish a statistical model to describe the relationship between the frequency of conspicuity-related motorcycle accidents and a range of explanatory variables so that new insights can be obtained into the effects of introducing a running headlight campaign and regulation. The exogenous variables in this analysis include the influence of time trends, changes in the recording and analysis system, the effect of fasting activities during Ramadhan and the ñBalik Kampongò culture, a seasonal cultural-religious holiday activity unique to Malaysia. The model developed revealed that the running headlight intervention reduced the conspicuityrelated motorcycle accidents by about $29 \%$. It is concluded that the intervention has been successful in improving conspicuity-related motorcycle accidents in Malaysia.
\end{abstract}

Keyword: Motorcycle accidents; Conspicuity; Running headlights; Generalized linear modelling 